\title{
The Impact Of Leadership Roles And Internships On Undergraduate Business Major Field Test (MFT) Scores
}

Chris Ward, University of Findlay, USA

Dan Yates, University of Findlay, USA

Joon Young Song, University of Findlay, USA

\begin{abstract}
It is often the goal or mission of higher education to prepare graduates for leadership roles in organizations and the community. Even if we are to assume that leadership skills can be developed, determining the appropriate ways to teach and measure leadership is often debated. Our study used quantitative data from the ETS Business Major Field Test (MFT) as an external measure and compared those results to specific items on a survey to determine if students who had leadership roles on campus or internships also scored higher on the ETS MFT test.
\end{abstract}

Keywords: Undergraduate Leadership; Internships; ETS MFT

\section{INTRODUCTION}

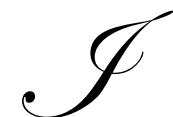

$\mathrm{t}$ is important to note the difference between management and leadership as these terms are often interchanged. Peterson and Peterson (2012) noted that managers have an official position in an organization and are accountable for achieving specific objectives and can influence people because of that position. Leaders, on the other hand, do not hold an official position but " ... can still influence members of the organization and by so doing influence the direction of the organization" (p. 103). These differences must not be taken lightly as students often assume they are not a leader unless they have a certain position in the group. Ferguson (2010) suggested every thinking person who comes in contact with others engages in critical leadership behaviors on a daily basis. "The important question is not whether a person is a leader, but whether he is maximizing his leadership opportunities" (p. 21).

Undergraduate leadership can be curricular or extra-curricular. Most business students will take a business management class and may even take a leadership class. We often wonder about the skills and dispositions acquired by students when taking these classes or leadership roles on campus. Leadership can be seen in a variety of ways. A student can be a project leader for a team project in a class, be an officer in a club or fraternity/sorority, lead a service-related community project, or they could be a team captain of a sport. Certainly, these skills and dispositions are valuable in the workplace and the development can begin early in a student's time spent at a university. This provides the student with an opportunity to learn and refine communication skills, understand the various types of leadership styles, then begin to develop a personal leadership style. Patterson (2012) noted "Leadership involved a versatile process that requires working with others in personal and professional relationships to accomplish a goal or promote positive change. Although leadership competencies and behaviors can be developed in many different ways, there has been an emerging consensus that leadership is transferred from one situation to another where one person emerges as a leader from a group" (p.1).

\section{CURRICULAR AND EXTRA-CURRICULAR OPPORTUNITIES}

Institutions have taken different approaches to developing leadership skills and dispositions for undergraduate students. Middleton (2013) stated it was “... imperative that emerging RN's have exposure to and 
experience in leadership skills and attributes that they may enter the workforce equipped" (p. 83). Through an active learning approach, an outline and learning outcomes were developed in order to engage the students and evaluate the development of leadership knowledge and skills. The following six learning outcomes were identified: Critically analyze theories of leadership, evaluate the dynamics of organizational culture, identify the knowledge, skills and behaviors required to lead, analyze the impact of leadership on team and team members, critically evaluate the impact of leadership skills on the delivery of healthcare practice and reflect on personal attributes in preparation for employment. The students were also expected to explore their personal values and understand there might be occasions where their personal values conflict with either the team or, more fundamentally, the culture of the organization. Specific active learning approaches were used including gauging the alignment of their personal values to those of the New South Wales (NSW) Australia and facilitating conversations on individual and team culture within an organization. Middleton (2013) felt strongly about the need for formal and long term evaluation and was especially supportive of the transformational leadership model as a way to develop students for a career in dynamic environments. She believes transformational leadership can be both learned and applied so students “... will have exposure to practice development principles and authentic leadership examples to develop themselves in preparation for practice" (p. 87).

The studies conducted by Gifford, Cannon, Stedman, \& Telg (2011) and Moore, Odom, \& Wied (2011) used a capstone project/experience to explore leadership. Students in the study by Moore, et al (2011) were required to write a "chapter" in a Leadership for Dummies book. This chapter assignment included, but was not limited to, a creative title based on the content of the chapter, a quotation related to the concept, pertinent information related to the concept selected, examples of how the material is to be learned and why it is relevant to everyday life, the development of assignments which included a reflective component, action items for the reader to practice, and craft the "Top Ten" takeaways for the reader. Gifford, et al (2011) used various iterations in a capstone course to find the balance between academics and application. While still under development, the course combines lecture with discussion and focuses on two major units - special event planning and professional growth, development, and career planning. The special event planning included the creation of an actual special event management proposal plan as a team while the professional portfolio included a resume, mock interview, and research on a particular industry of interest, etc. While the student feedback varied, the authors noted an overall lack of post-graduation planning as well as a lack of knowledge regarding the career preparation resources available to them. The purpose of capstone courses is thus debatable. Should these courses simply be a knowledge synthesizing mechanism leveraging the department's curriculum or move entirely to an application of the higher order skills in Bloom's Taxonomy and expect students to demonstrate leadership dispositions?

Other authors focused on a narrower group of students for their studies. Peterson and Peterson (2012) and Patterson (2012) studied students as members or leaders of student organizations while Hall, Forrester, and Borsz (2008) looked at undergraduate students in campus recreational sports and Grandzol, Perlis and Driana (2010) focused on the leadership development of team captains in collegiate varsity athletics. Peterson and Peterson (2012) used the Managerial Leadership Instrument (MLI) and instructed the participants to mark behaviors they believed critical to their organization's ability to achieve its purpose. The students identified the following behaviors as critical: builds trust, takes the initiative, is friendly and considerate, builds a team, inspires members, delegates authority, informs about responsibility, and keeps employees informed. The authors then compared these critical behaviors to behaviors deemed critical in for-profit, non-for-profit and military managers and found that most of the behaviors identified as important by the students corresponded to behaviors expected in profit, non-for-profit and military managers. An important implication of this study is that if we teach students the eight managerial leadership behaviors identified and "allow them to practice these behaviors in their student organizations, it would pay dividends for these students when they enter the workforce, whether that is in the for-profit, non-for-profit or military sector" (p. 113).

Patterson (2012) stated "Participation in organizational leadership experiences provides participants with the opportunity to interact with their peers in formal and non-formal leadership training" (p.2). Using the Leadership Practices Inventory (LPI), their survey explored leadership practices but also considered organizational leadership experiences and gathered demographic information. Their findings indicate that "collegiate clubs and organizations are influential in terms of developing leadership and should be supported" but also found "... some of the most effective leadership development opportunities seem to be with interdisciplinary organizations" (p. 7). 
When Hall, et al (2008) examined leadership development of undergraduate students in campus recreational sports, they found "Students gained organizing, planning, and delegating skills as a result of their leadership experience in the areas of finance and budgeting as well as in organizing and facilitating meetings" (p. 130). The students were also able to develop their oral and written communication skills through careful review of emails, taking more time to organize their thoughts and speaking in front of a room of 20-40 fellow students. Students were challenged by and reflected how to balance their academic expectations, work, and leadership roles. The final study examined the leadership development of team captains in collegiate varsity athletics.

Grandzo, et al (2010) used the Student LPI and found "Team captains demonstrated higher levels of all five leadership practices than team members" (p. 414). An interesting note by the authors was the "... choice of team captain may be based on the captains' perceived leadership abilities and not their year in school, athletic success, popularity, etc., as could be argued" (p. 414). In addition, it appeared that although the team captains did not get any formal leadership training, the experience of being a role model, learning from mistakes, and finding ways to celebrate accomplishments (individual or team) was beneficial.

While there is a wide variety of ways for students to participate in leadership roles, it is often difficult for some students to recognize themselves as leaders especially if they are not in a team captain or club officer role. Our research focused on leadership roles in student government, resident assistant, and club officer.

\section{METHODOLOGY AND RESULTS}

For the past several years, we have implemented a self-administered engagement survey to students in a capstone class and, at the same time, the students take the ETS Business MFT. The overall benchmarks of Level of Academic Challenge, Active and Collaborative Learning, Enriching Educational Experiences and Integration of Diversity into Coursework were compared to ETS MFT scores. As of spring 2013, we had a sample size of 137. The sample is balanced between males (50.4\%) and females (49.6\%) with most of the students having senior status (78.8\%). When running OLS regression, Enriching Educational Experiences was the only benchmark showing a significant positive relationship to the ETS MFT (see Table 1).

Table 1: OLS Regression between NSSE benchmarks and ETS MFT

\begin{tabular}{|l|c|}
\hline Level of Academic Challenge & $-1.025^{*}$ \\
\hline Active and Collaborative Learning & .564 \\
\hline Enriching Educational Experiences & $.723^{* * *}$ \\
\hline Integration of Diversity into Coursework & .653 \\
\hline
\end{tabular}

$*, * *, * * *$ indicates significance at the $10 \%, 5 \%$ and $1 \%$, respectively

Of specific interest to the authors was the relationship between ETS MFT and Enriching Educational Experiences items. These items included doing an internship, holding a leadership position, working off campus and co-curricular activities. OLS Regression was used to determine the relationship between specific items of student engagement and both GPA and MFT.

Table 2 shows the additional results of our study for specific items within the Enriching Educational Experiences which focused on internships, leadership positions on campus, working on campus and co-curricular activities. This is supported by Moore and Rago (2009) as they found those students who were motivated to work to gain experience in their field of study by working on or off campus, “... reported in higher levels of engagement in all five benchmarks" (p. 98). The authors made an additional observation noting " ... students who worked off campus and who were more motivated to work to pay for books and supplies reported experiencing higher levels of academic challenge and saw the campus as more supportive" (p. 98) while those who worked on campus "... reported higher levels of active and collaborative learning" (p.98).

Table 2: OLS Regression between specific Enriching Educational Experiences and the ETS MFT

\begin{tabular}{|l|c|}
\hline Internship & $1.997 * *$ \\
\hline Held a leadership position on campus & $2.837 * * *$ \\
\hline Worked off campus & -.401 \\
\hline Co-curricular activities & .700 \\
\hline$, * *, * * *$ indicates significance at the $10 \%, 5 \%$ and $1 \%$, respectively
\end{tabular}


The results in Table 2 show a significant positive relationship between students who have completed an internship as well as students who have held a position of leadership on campus and higher ETS MFT scores. We can assume these students are learning information in the classroom then actively demonstrate this during their internships experience. Students who have completed internships often have a renewed interest in learning, are more focused, and typically elevate their level of work. Students in leadership positions often need to plan, organize and execute events, work with multiple offices on campus, develop budgets, and motivate members to become engaged. These skills mirror the LPI attributes mentioned earlier in the paper. In addition, as a part of the event summary, the clubs are required to report attendance at events and encouraged to seek feedback from participants. These activities closely resemble the Kouzes and Posner's Leadership Practices of Modeling the Way, Enabling Others to Act, Inspiring a Shared Vision, Challenging the Process, and Encouraging the Heart. We were a bit surprised regarding the negative relationship between working off-campus and ETS MFT scores, however, our findings were similar to those in Salisbury, et al (2012) as they indicated "Working off campus more than 20 hours/week had significant negative indirect effects on total leadership, group leadership, and leadership for change" (p. 315). They assumed this is due to fewer interactions with their peers and less time to get involved in activities on campus. Additionally, we looked at students who worked on campus and their ETS MFT scores. The independent samples t-test showed no significant difference at the 0.05 level of significance between students who did or did not work on campus and ETS MFT scores. Moore and Rago (2009) “... reported higher levels of active and collaborative learning" (p. 98) for those students who worked on campus but no impact on engagement. It is important to note that our co-curricular activities included community service, school based clubs, community based clubs, intercollegiate sports, creative or performing arts, on campus work, campus publications, fraternity and sorority, resident assistant and admissions/orientation ambassador. Due to the variety of the co-curricular activities listed in our survey, we were not surprised it was not significant with higher ETS MFT scores.

Additional statistical analysis was conducted to gain further insight into the data. We conducted a chisquare test to test the following hypothesis:

$\mathbf{H}_{\mathbf{0}}$ : There is no dependency between students' holding a leadership position on campus and completing an internship.

$\mathbf{H}_{\mathrm{a}}$ : Students who have held a leadership position on campus are likely to complete an internship

The test results indicate that we fail to reject the alternative hypothesis. There is statistically significant evidence that supports the dependency between students' holding a leadership position on campus and completing an internship.

A Binary Logit Regression Model was also used to see how students' academic performance (GPA) and their demographic categories (Gender and Class) related to the likelihood of doing an internship. The data showed that students who have held a leadership position on campus are 2.22 times more likely to complete an internship than students who have not had a leadership position ( 0.05 significance level) and female students are 3.95 times more likely to complete an internship than male students ( 0.01 significance level). In addition, students are more likely to have an internship as their GPA increases. This last point could be attributed to major employers not accepting students with a GPA below a 3.0.

The results of our study reinforces the concept that high impact practices, like internships, do lead to higher scores on content knowledge based tests such as the ETS Business MFT. In addition, we should encourage students early in their academic career to seek out leadership roles in curricular or extra-curricular activities.

\section{CONCLUSION}

Graduates are still in a competitive environment for good jobs. The goal of leadership experiences should be to assist them in fine tuning their skills in order to be more attractive to employers (Gifford, et al, 2011). Whether these experiences are curricular or extra-curricular, they do provide the foundation for students to move through the continuum of learning about the various leadership styles and theories to practicing and reflecting on their personal leadership style. 
Moore and Rago (2009) agreed by stating "If students who see connections to their future interests perform better in school, then university administrators need to develop techniques that assist them in seeing these connections in their employment" (p. 101). Ferguson (2010) provided a comment for inspiration to meet this challenge when he stated "I believe that any students who embark on leadership development at the undergraduate level have an exponential advantage over the people they otherwise would have been when it comes to impact, influence and making a difference in the world around us" (p. 24). This should challenge us as educators to engage students early, encourage them to do internships, and support their roles as campus leaders, no matter how those roles might emerge.

\section{FUTURE RESEARCH}

Several opportunities emerge for future research. While our findings are interesting, the results are limited to business students. We are curious whether similar results would be found for other disciplines who also administer the ETS MFT. Current plans are underway to solicit other disciplines, specifically criminal justice and biology, to join our study. It may, however, take several semesters to obtain a sample size large enough to provide a valid comparison and meaningful results. In addition, by interviewing student leaders, we could learn if certain advisers, professors or specific courses motivated the student to seek leadership positions.

\section{AUTHOR INFORMATION}

Dr. Chris Ward is an Associate Professor of Business with The University of Findlay. Professor Ward brings her expertise from two Fortune 500 companies into the classroom teaching marketing, management, and research.

Professor Ward holds the following degrees: University of Sarasota, EdD, Organizational Leadership; The University of Findlay, MBA and The University of Findlay, Bachelor of Science in Business Administration. She is also a Six Sigma Black Belt, a 2008 Ohio Partnership for Excellence Examiner, and completed the NxLevel Certification Course for Instructor Certification for teaching business plans. Her areas of research include student engagement, active learning, assessment and personal branding.

Dr. Dan Yates is an Associate Professor of business at The University of Findlay. His teaching interests include entrepreneurship, leadership, organization development, and business strategy. Yates holds a $\mathrm{PhD}$ degree in Management from Northcentral University. He also has a MBA from University of Dayton, a Master of Organization Development degree from Bowling Green State University, and a BS in Accounting from Tiffin University. He completed the NxLevel Certification Course for Instructor Certification for teaching business plans at the Innovation Center (Ohio University). He has 30 years industrial and governmental experience and his research interest are active learning and personal finance.

Dr. Joon Young Song is an Associate Professor of Finance at the University of Findlay. Prior to joining the University of Findlay, Dr. Song has worked for a nation-wide business newspaper and a researcher at the LG Economic Research Institute in Korea. Professor Song earned a doctoral degree in business administration with concentration of finance from University of Tennessee (Knoxville). He also holds several master degrees in business administration and economics from Seoul National University, Syracuse University, and the University of Tennessee. His current research interests are in the areas of Asset Pricing, Behavioral Finance, and Corporate Governance.

\section{REFERENCES}

1. Ferguson, D. (Spring 2010). Why an Undergraduate Leadership Program? Journal of Applied Christian Leadership, 4(1), 18-24.

2. Gifford, G. T., Cannon, K. J., Stedman, N., \& \& Telg, R. W. (Winter 2011). Preparation for Full Time Employment: A Capstone Experience for Students in Leadership Programs. Journal of Leadership Education, 10(1), 103-114.

3. Grandzol, C., \& Perlis, S. \&. (July/Aug 2010). Leadership Development of Team Captains in Collegiate Varsity Athletics. Journal of College Student Development, 51(4), 403-418. 
4. Hall, S., \& Forrester, S. \&. (March/April 2008). A Constructivist Case Study Examining the Leadership Development of Undergraduate Students in Campus Recreational Sports. Journal of College Student Development, 49(2), 125-140.

5. Komives, S., Owen, J., Lonferbeam, S., \& Mainella, F. \&. (Nov/Dec 2005). Developing a Leadership Identity: A Grounded Theory. Journal of College Student Development, 46(6), 593-611.

6. Middleton, R. (2013). Active Learning and Leadership in an Undergraduate Curriculum: How Effective is it for Student Learning and Transition to Practice. Nurse Education in Practice, 83-88.

7. Moore, L., Odom, S., \& \& Weid, L. (Winter 2012). Leadership for Dummies: A Capstone Project for Leadership Students. Journal of Leadership Education, 10(1), 123-131

8. Moore, J. V., \& Rago, M. (2009). The Impact of Employment on Student Engagement: Results from NSSE. In B. Perozzi (Ed.), Enhancing Student Learning Through College Employment (p. 87-107). Bloomington, IN: Association of College Unions International.

9. Nunez, E. M. (Winter 2013). Collaborative Leadership on a Liberal Arts Campus. Peer Review - AAC\&U, 17-20.

10. Patterson, B. (Spring and Summer 2012). Influences of Student Organizational Leaderhip Experiences in College Students Leadership Behaviors. e-Journal of Organizational Learning and Leadership, 10(1), 112.

11. Peterson, T. \&. (Winter 2012). What Managerial Leadership Behaviors do Students Managerial Leaders Need? An Empirical Study of Student Organizational Members. Journal of Leadership Education, 11(1), 102-120.

12. Posner, B. Z. (July/Aug 2004). A Leadership Development Instrument for Students: Updated. Journal of College Student Development, 45(4), 443-456.

13. Salisbury, M., Pascarella, E., \& Padgett, R. D. (March/April 2012). The Effects of Work on Leadership Development Among First-Year College Students. Journal of College Student Development, 53(2), 300324. 